\title{
Combining Chondrocytes and Smooth Muscle Cells to Engineer Hybrid Soft Tissue Constructs
}

\author{
ANDREA N. BROWN, B.S., ${ }^{1}$ BYUNG-SOO KIM, Ph.D., ${ }^{1}$ EBEN ALSBERG, M.S.E., ${ }^{2}$ \\ and DAVID J. MOONEY, Ph.D. ${ }^{1-3}$
}

\begin{abstract}
Engineering new tissues using cell transplantation may provide a valuable tool for reconstructive surgery applications. Chondrocyte transplantation in particular has been successfully used to engineer new tissue masses due to the low metabolic requirements of these cells. However, the engineered cartilaginous tissue is too rigid for many soft tissue applications. We propose that hybrid tissue engineered from chondrocytes and smooth muscle cells could reflect mechanical properties intermediate between these two cell types. In this study, rat aortic smooth muscle cells and pig auricular chondrocytes were co-cultured on polyglycolic acid fiber-based matrices to address this hypothesis. Mixed cell suspensions were seeded by agitating the polymer matrices and a cell suspension with an orbital shaker. After seeding, cell-polymer constructs were cultured in stirred bioreactors for 8 weeks. The cell density and extracellular matrix (collagen, elastin, and glycosaminoglycan) content of the engineered tissues were determined biochemically. After 8 weeks in culture, the hybrid tissue had a high cell density $\left(5.8 \times 10^{8} \mathrm{cells} / \mathrm{cm}^{3}\right)$, and elastin $(519 \mu \mathrm{g} / \mathrm{g}$ wet tissue sample $)$, collagen $(272 \mu \mathrm{g} / \mathrm{g}$ wet tissue sample), and glycosaminoglycan (GAG; $10 \mu \mathrm{g} / \mathrm{g}$ wet tissue sample) content. Mechanical testing indicated the compressive modulus of the hybrid tissues after 8 weeks to be $40.8 \pm 4.1 \mathrm{kPa}$ and the equilibrium compressive modulus to be $8.4 \pm 0.8 \mathrm{kPa}$. Thus, these hybrid tissues exhibited intermediate stiffness; they were less stiff than native cartilage but stiffer than native smooth muscle tissue. This tissue engineering approach may be useful to engineer tissues for a variety of reconstructive surgery applications.
\end{abstract}

\section{INTRODUCTION}

Ynthetic materials and tissue grafts have been used conventionally in plastic and reconstructive surgery
to replace damaged or defective tissues. Synthetic prosthesis (e.g., metals, ceramics, and plastics) can
be fabricated reproducibly in large quantities with well-defined properties, and lead to aesthetic improve-
ment. However, these materials do not faithfully mimic the properties of native tissues, and the long-term
implantation of synthetic materials can give rise to infection and/or rejection from the body. ${ }^{1}$ Alternatively,
tissue transplantation (e.g., cartilage) has often been used to replace damaged and defective tissues. For ex-
ample, autogeneous cartilage used as a free graft for cosmetic improvement has produced excellent results.

Departments of ${ }^{1}$ Chemical Engineering, ${ }^{2}$ Biomedical Engineering, and ${ }^{3}$ Biologic and Materials Sciences, University of Michigan, Ann Arbor, Michigan. 


\section{BROWN ET AL.}

In plastic surgery, craniofacial and aesthetic surgeons have strived to use this technique for reconstructing osseocartilaginous craniofacial skeleton using cartilage and bone grafts. ${ }^{2}$ However, the scarcity of usable tissue, donor site morbidity, and scarring limit the application of tissue transplants.

A new approach to generate tissues for reconstructive and plastic surgery is to engineer functional, natural tissues using three-dimensional scaffolds and cultured cells. ${ }^{3}$ Expanding cells in culture may allow a virtually unlimited supply of tissue to be created from an initially small tissue biopsy. The scaffolds for tissue engineering can be fabricated from a variety of naturally derived materials (e.g., type I collagen, alginate, hydroxyapatite) or synthetic biodegradable polymers [e.g., polyglycolic acid (PGA), polylactic acid, and poly(lactic-co-glycolic) acid]. ${ }^{4}$ Cells seeded onto the scaffolds are either allowed to develop into a new tissue in vitro or transplanted into a patient to create a functional tissue that is structurally integrated with the body. ${ }^{5}$ Tissue engineering principles are being applied to repair, replace, maintain, or enhance the function of a large number of different tissues and organs. ${ }^{3}$

Methods to engineer cartilage using biodegradable polymers and cultured cells have been extensively investigated because many aspects of chondrocytes make them ideal for tissue engineering. ${ }^{2,6-11}$ These cells have a very low metabolic activity, and thus survive exceptionally well following transplantation with minimal nutrient availability. Chondrocytes are well adapted to conditions where the oxygen tension may be as low as $1 \%$ (compared with $24 \%$ in normal atmosphere). Indeed, pieces of cartilage several millimeters in thickness can be engineered by transplanting chondrocytes on biodegradable polymer matrices. ${ }^{11,12}$ This contrasts with most cell types, which are susceptible to hypoxia and thus cannot be used to form tissues more than several hundred micrometers thick unless a vascular supply is provided. ${ }^{13,14}$ An additional advantage of chondrocytes is that these cells can be readily multiplied in culture. However, while the high strength and stiffness of the tissues engineered with chondrocytes make them ideal for cartilage replacement, these properties make the tissues unsuitable for soft tissue replacement in many plastic and reconstructive surgery applications.

To engineer suitable tissues that can be used in the reconstruction of soft tissues, we propose to engineer tissues from a combination of chondrocytes and other cell types. These tissues may allow us to readily engineer large tissues (due to low metabolic activity of chondrocytes) that have mechanical properties intermediate to cartilage and soft tissues. In the present study, we determined whether the addition of smooth muscle cells would decrease the rigidity of tissues engineered using chondrocytes in vitro. In addition, chondrocytes derived from auricular cartilage were utilized, because auricular cartilage is typically less rigid than articular cartilage.

\section{MATERIALS AND METHODS}

\section{Cell isolation}

Porcine auricular chondrocytes (passage $=0$ and 1 ) donated by Reprogenesis (Cambridge, MA) were used in all experiments. The chondrocytes were maintained in DMEM/F-12 (GIBCO, Gaithersburg, MD) containing $10 \%$ (vol/vol) fetal bovine serum (FBS; GIBCO) and $100 \mathrm{U} / \mathrm{mL}$ penicillin-streptomy cin (GIBCO). Cells were cultured in tissue culture flasks (Corning Inc., Corning, NY) in a humidified $5 \% \mathrm{CO}_{2}$ incubator with growth medium changed once a week (twice a week when approaching confluence). Cells of passages 1-4 were used for all experiments. Smooth muscle cells (SMCs) were isolated from 300-350 g adult male Lewis Rats using an enzymatic dissociation and cultured as previously described. ${ }^{15}$ SMCs were maintained in Medium 199 (GIBCO) containing 10\% (vol/vol) FBS (GIBCO) and $100 \mathrm{U} / \mathrm{ml}$ penicillin-streptom ycin (GIBCO) with the growth medium changed every other day. Cells of passages 12-18 were used for all experiments.

\section{Polymer scaffolds}

PGA fiber-based matrices (2-mm thick) with a bulk density of $50 \mathrm{mg} / \mathrm{mL}$ and porosity of approximately 97\% were purchased from Albany International (Taunton, MA) and stored in a dessicator before use. The PGA matrices were cut $(5 \times 5$-mm squares for biochemical assay and simple compression test specimens and 12.6-mm diameter disks for viscoelastic testing specimens) and sterilized under UV light for a 10-h pe- 
riod on each side. They were prewet in a petri dish containing $70 \%$ ethanol and rinsed $(4 \times)$ in phosphatebuffered saline (PBS; GIBCO). The scaffolds were then transferred into 50-ml tubes with $25 \mathrm{ml}$ of the medium containing 45\% (vol/vol) DMEM/F12, 45\% (vol/vol) Medium 199, 10\% (vol/vol) FBS, and 100 $\mathrm{U} / \mathrm{mL}$ penicillin-streptomycin. The closed tubes were placed in an incubator for $24 \mathrm{~h}$ prior to seeding to allow the adsorption of proteins contained in the serum onto the PGA fibers for cell attachment.

\section{Cell seeding and culture}

Matrices were seeded with equal numbers of chondrocytes and SMCs (total cell concentrations in the seeding solution were $5.4 \times 10^{7}$ cells $/ \mathrm{mL}$ for the biochemical assay and simple compression test specimens and $4.6 \times 10^{7}$ cells $/ \mathrm{mL}$ for the viscoelastic testing specimens) using an agitated cell seeding method. ${ }^{16}$

To seed cells, the polymer matrices were placed into either $50-\mathrm{mL}$ tubes with $0.3 \mathrm{~mL}$ of a cell suspension or into wells of a 24-well tissue culture plate (Falcon, Franklin Lakes, NJ) with $0.4 \mathrm{~mL}$ of a cell suspension. The polymers were then agitated with the cell suspension at $100 \mathrm{rpm}$ for $20 \mathrm{~h}$ in a humidified $5 \%$ $\mathrm{CO}_{2}$ incubator using an orbital shaker (Belco Glass Inc., Vineland, NJ). Ten hours after agitation had begun, a volume of media equal to that of the original cell suspension volume was added to each matrix. Following the agitation, the scaffolds were transferred to a $150 \times 15-\mathrm{mm}$ petri dish (Falcon) for 3 days with $50 \mathrm{~mL}$ of media changed every day. Following the cell seeding, cell-polymer constructs were maintained in 250-mL spinner flasks (Belco Glass, Inc.) stirred at $26 \mathrm{rpm}$ in a humidified $5 \% \mathrm{CO}_{2}$ incubator for 8 weeks with medium containing $0.5 \mu \mathrm{g} / \mathrm{mL}$ ascorbic acid changed every other day. During the culture period, samples collected for analytical assays were washed with PBS prior to analysis.

\section{Analytical assays}

For histological analysis, samples were fixed in $10 \%$ (vol/vol) buffered formalin, paraffin embedded, sectioned, and stained with hematoxylin and eosin (H\&E), Verhoeff's, or Safranin-O.

The number of cells in the matrices was determined by measuring the amount of DNA in enzyme-digested samples with Hoechst 33258 dye and a fluorometer (Hoefer Dyna Quant 200, Pharmacia Biotech, Uppsala, Sweden) using a previously described technique. ${ }^{17}$ In brief, the samples were washed with PBS, lyophilized for $24 \mathrm{~h}$, and digested in proteinase $\mathrm{K}$ digestion solution $(0.5 \mathrm{mg} / \mathrm{mL}$ proteinase $\mathrm{K}$ and 0.1 $\mathrm{mg} / \mathrm{mL}$ SDS in a buffer solution of $50 \mathrm{mM}$ Tris- $\mathrm{HCl}, 0.1$ EDTA, $0.2 \mathrm{M} \mathrm{NaCl}, \mathrm{pH} 7.4$ ) for $12 \mathrm{~h}$ at $60^{\circ} \mathrm{C}$ with occasional gentle shaking. For measurement, 20-50 $\mu \mathrm{L}$ of sample was aliquoted into a cuvette and mixed with $2 \mathrm{~mL}$ of dye solution. A solution containing calf thymus DNA (Pharmacia Biotech) was used for calibration. The presence of the polymer scaffold does not interfere with the quantification of DNA in this assay. Assaying samples in which known amounts of DNA were added to blank polymer scaffolds leads to the expected DNA concentration (data not shown).

Commercially available assay kits (Fastin elastin, collagen, and glycosoaminoglycan (GAG) assay kits, Accurate Chemical \& Scientific Corp., Westbury, NY) were used for the measurement of elastin, collagen, and GAGs within the samples. The elastin assay was designed for the measurement of insoluble elastin. The elastin-polymer constructs were solubilized by hot oxalic acid treatment for three 1-h intervals at $95^{\circ} \mathrm{C}$. The samples were then precipitated overnight in a $5^{\circ} \mathrm{C}$ refrigerator with Fastin precipitating reagent to allow precipitation of the elastin. Following precipitation, the samples were centrifuged and the pellets were mixed with Fastin dye reagent. The elastin-dye complex was then collected by centrifugation. The dye bound to the elastin pellet was solubilized with the destain reagent, and the absorbance of the samples was measured at a wavelength of $513 \mathrm{~nm}$ using a UV spectrophotometer. A calibration standard containing $\alpha$ elastin was used to obtain the standard curve for this experiment.

The GAG assay was designed for the measurement of soluble GAG within a tissue sample. GAG was extracted from the polymer constructs using a solvent system of $4 \mathrm{M}$ guanidine- $\mathrm{HCl}, 0.5 \mathrm{M}$ sodium acetate, pH 6, with $1 \mathrm{mM}$ benzamidine-HCl, $1 \mathrm{mM}$ phenylmethylsulfonyl fluoride (PMSF), and $10 \mathrm{mM} \mathrm{N}$-ethylmaleimide (NEM). ${ }^{18,19}$ The constructs were added to the chilled solution with stirring on an orbital shaker for a 12 - to 20 -h period at $4{ }^{\circ} \mathrm{C}$. After the extraction, the samples were centrifuged to remove insoluble residue and the supernatant was collected and mixed with blyscan dye reagent (composed of 1,9-dimethylmethylene blue in an organic buffer) for $30 \mathrm{~min}$. The glycosaminoglycan-dye complex was collected by 


\section{BROWN ET AL.}

centrifugation. The dye bound to the pellet was solubilized by adding a dissociation reagent and mixing until the bound dye was released into solution. The absorbance of the samples was measured at a wavelength of $656 \mathrm{~nm}$ using a UV spectrophotometer. A calibration solution containing chondroitin-4 sulfate was used to obtain the standard curve for this experiment.

The total collagen content (salt, acid, and pepsin soluble fractions) of the tissues was also quantified. ${ }^{20}$ The salt-soluble collagen was extracted from the tissue samples by incubating tissues at $5^{\circ} \mathrm{C}$ with a series of $\mathrm{NaCl}$ buffer solutions containing protease inhibitors (EDTA $20 \mathrm{mM}$, PMSF, NEM). The salt buffers were collected for later analysis. The acid-soluble collagen was subsequently removed from the remaining tissue by adding $0.5 \mathrm{M}$ acetic acid to the samples and incubating at room temperature. The acid solution containing dissolved collagen was collected for later analysis, and the pepsin-soluble collagen was subsequently extracted from the remaining tissue. A solution containing pepsin $(1 \mathrm{mg} / 10 \mathrm{mg}$ tissue sample; Sigma, St. Louis, MO) was added to the tissues and incubated overnight. The salt-soluble, acid-soluble, and pepsinsoluble samples were collected and combined for total soluble collagen content. This sample was prepared for assay by mixing with Sircol dye reagent for $30 \mathrm{~min}$ on an orbital shaker. The samples were then centrifuged to collect the collagen-dye complex. The dye bound to the collagen pellet was solubilized with an alkali reagent, and the absorbance of the samples was measured at a wavelength of $540 \mathrm{~nm}$ using a UV spectrophotometer. A calibration standard of acid-soluble type I collagen was used to obtain the standard curve for this experiment. ECM contents were normalized to the wet mass of the new tissues for all assays.

\section{Mechanical testing}

Following measurement of 8 -week polymer-construct thickness and cross-sectional area with calipers, simple compression tests were performed using a MTS Bionix 100 (Model 810, MTS Systems Corp., Eden Prairie, MN) with a $10 \mathrm{~N}$ load cell and a cross-head speed of $1 \mathrm{~mm} / \mathrm{min}$. Stress versus strain curves were then generated using the force and displacement data. The compressive moduli were obtained by measuring the slope of the first $5 \%$ of the stress-strain curve where the stress was non-zero $(n=4)$.

Viscoelasticity tests were also performed using a similar method employed for materials such as cartilage ${ }^{21}$ and hydrogels. ${ }^{22}$ The thickness and cross-sectional area of specimens to be tested were measured. Using a custom testing fixture, the specimens were submerged in medium at $37^{\circ} \mathrm{C}$ and placed at the bottom of an aluminum well $6.3 \mathrm{~mm}$ diameter by $3 \mathrm{~mm}$ deep. The specimens communicated with the medium through a 3.2$\mathrm{mm}$-thick porous stainless steel filter with an average pore size of 20 microns (SSI Technologies Inc., Janesville, WI). The compression tests were unconfined in the radial direction because specimen diameters were less than the well diameter. A confined compression test would be ideal, however, this test could not be used because the samples did not have an identical size and shape, and the tissues could not be cut due to their spatially inhomogeneous nature. Specimens were compressed at a rate of $5 \mathrm{~mm} / \mathrm{min}$ in step strains of $\sim 4 \%$. After each step strain, the strain was held constant for $10 \mathrm{~min}$ or until an equilibrium stress state was reached. Equilibrium stress-strain curves were obtained and longitudinal moduli were calculated using the secant slope of the first 5\% of the interpolated equilibrium stress-strain curves where the stress was non-zero $(n=5)$.

\section{Statistical analysis for assays}

All data were obtained from a minimum of triplicate samples. Data were expressed as the mean and standard deviation (SD). Statistical analysis was carried out using the unpaired Student's $t$-test (Instat, Graphpad Software Inc., San Diego, CA). A value of $p<0.05$ was considered to be statistically significant.

\section{RESULTS}

A combination of equal numbers of chondrocytes and SMCs were seeded onto polymer matrices. The cells adhered to the polymer fibers as individual cells and cell clusters, and proliferated on the matrices. Solid new tissues resulted over the course of 8 weeks in spinner flask culture. Tissue samples were fixed, sectioned, and stained to histologically examine the engineered tissues. Observation of sections stained with $\mathrm{H} \& \mathrm{E}$ after 8 weeks in culture indicated the proliferation of cells throughout the polymer matrices and the 
accumulation of an extracellular matrix in the engineered hybrid tissues (Fig. 1A). The engineered tissues had a higher density of cells on the outer layer of the constructs, and a lower density of cells in the center.

The major ECM molecules in cartilage and smooth muscle include elastin, collagen, and GAGs. Verhoeff's staining of the histologic sections indicated that the hybrid tissues contained substantial elastin at 8 weeks (Fig. 1B). More elastin was present in the outer layer of the hybrid tissue than in the inner portion, suggesting that SMCs are preferentially distributed to the outer layer rather than the center of these engineered tissues. Safranin-O staining was done to verify the presence of a cartilaginous tissue, and histological sections exhibited positive staining for GAG. The hybrid tissue exhibited a more prominent staining in the interior, again consistent with a preferential distribution of chondrocytes in the inner layer of the tissues (data not shown).
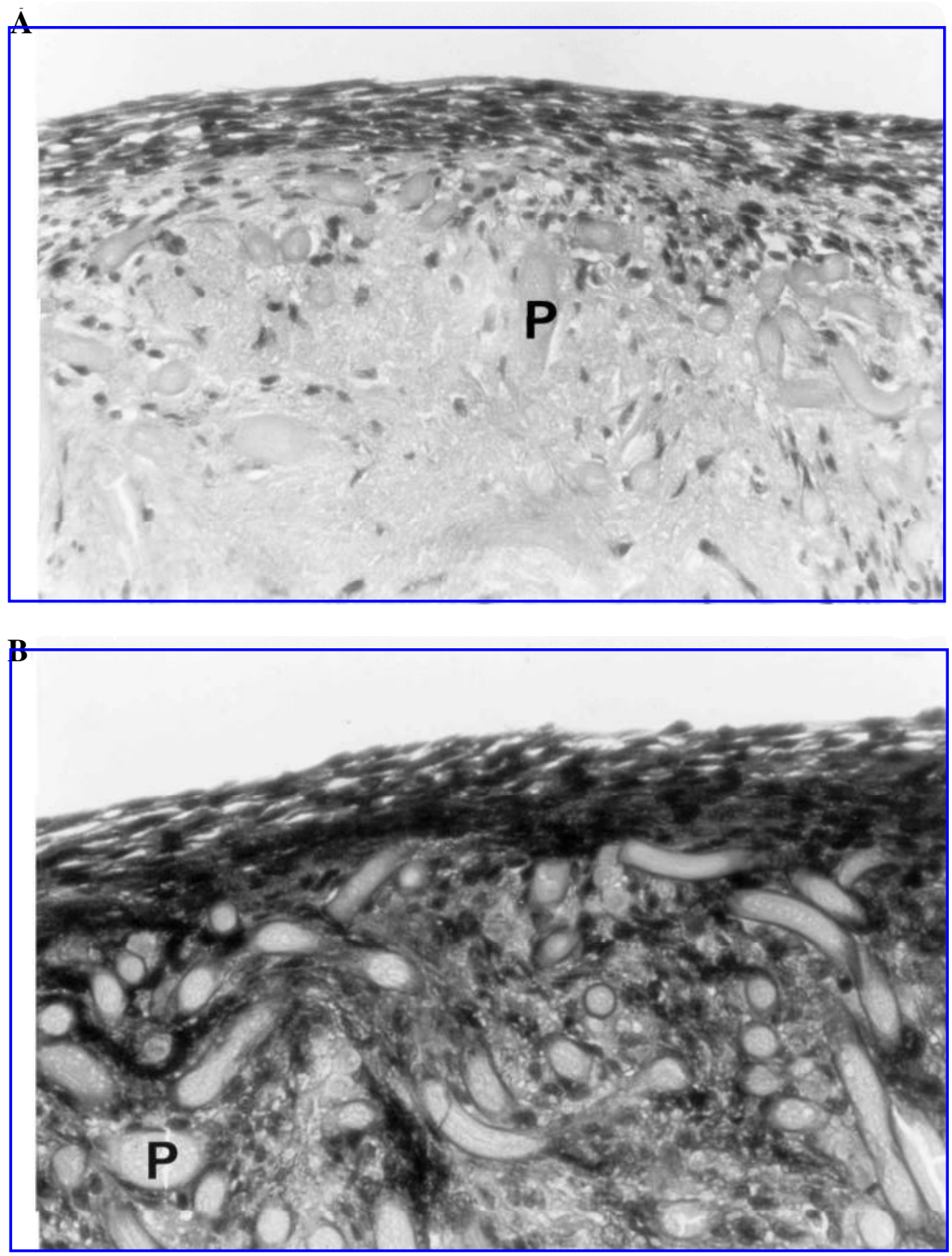

FIG. 1. Representative photomicrographs of H\&E stained histologic sections (A) and Verhoeff-stained sections of tissues engineered from a combination of SMCs and chondrocytes after 8 weeks of culture (B). Polymer fibers (P) are visible. (Original magnification: $40 \times$ for both photomicrographs.) 


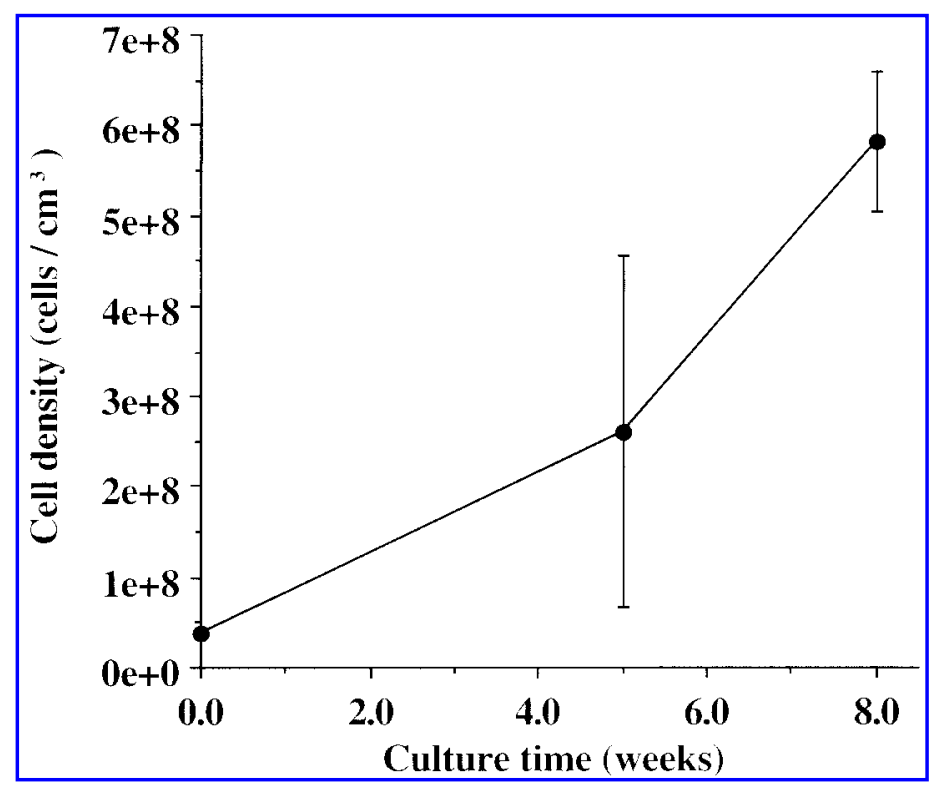

FIG. 2. The cell density of hybrid tissues cultured for 8 weeks. Data points represent the average \pm standard deviation (SD) of triplicate samples.

The cell density and ECM composition of the engineered tissues were also quantified over time. The cell density of the engineered tissues was determined by measuring the DNA content in the tissue constructs. The cell density increased dramatically over time and after 8 weeks in culture the engineered tissues had a cell density of $5.8 \times 10^{8}$ cells $/ \mathrm{cm}^{3}$ (Fig. 2). The cell density had increased $123 \%$ from 5 to 8 weeks in culture. The extracellular matrix components also increased significantly during the culture of the hybrid tissues. The elastin, collagen, and GAG content of the hybrid tissue also increased over time to 8-week values of 519, 272, and $10 \mu \mathrm{g} / \mathrm{g}$ wet tissue sample, respectively (Fig. 3). The increases from 5 to 8 weeks were significant $(p<0.003$ in all cases $)$.

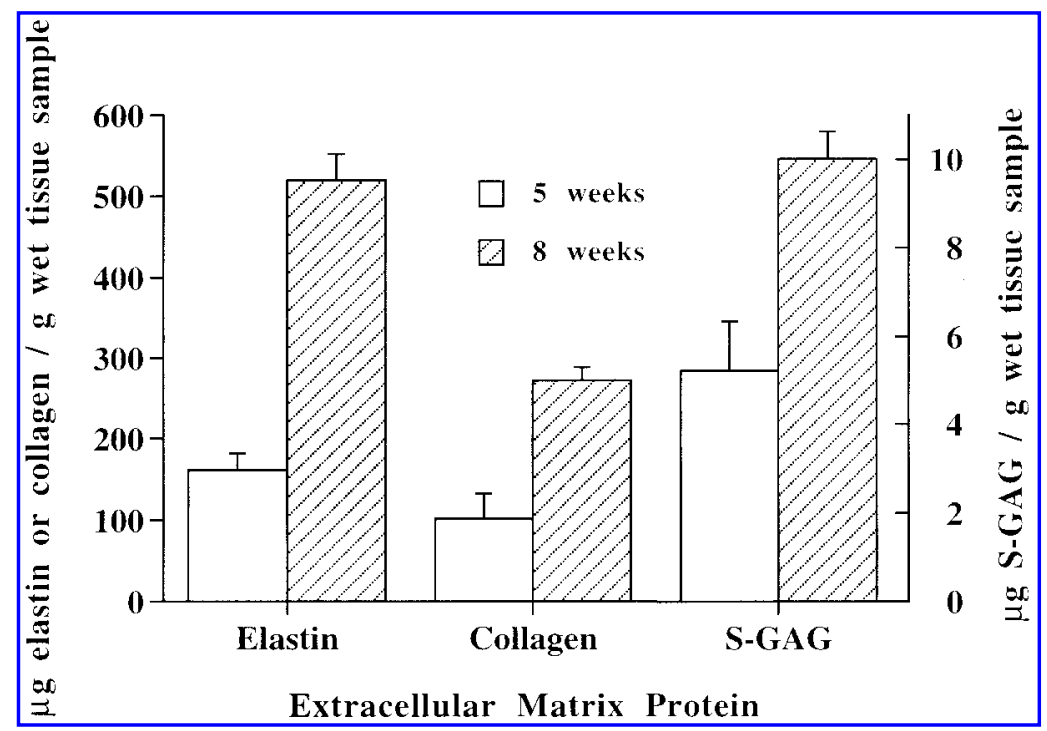

FIG. 3. Content of elastin, collagen, and sulfated glycosaminoglycan (S-GAG) per gram wet tissue sample after 5 and 8 weeks of culture for the hybrid tissues. Data points represent the average \pm standard deviation (SD) of triplicate samples. 
The elastic modulus of the engineered tissues was next measured using two different techniques. One group of specimens was subjected to simple uniaxial compression tests at a constant strain rate. Stress-strain curves (Fig. 4A) were constructed from load-displacement data and the average compressive modulus of the hybrid tissues was found to be $40.8 \pm 4.1 \mathrm{kPa}$. Because moduli determined with this method are strain rate dependent, a more complex viscoelastic technique was then employed for another group of specimens. Small step strains were applied to the specimens and held constant until an equilibrium stress state was achieved. The specimens demonstrated significant stress relaxation after each step strain (Fig. 4B). The steady-state data were then used to construct equilibrium stress-strain curves (Fig. 4C) from which the average equilibrium compressive modulus was calculated $(8.4 \pm 0.8 \mathrm{kPa})$. This represents approximately a five-fold difference in modulus, depending on whether perfectly elastic behavior or viscoelastic characteristics of the tissues were assumed to perform the mechanical test.

\section{DISCUSSION}

Hybrid tissues composed of SMCs and chondrocytes were engineered using biodegradable polymer matrices. These hybrid tissues exhibited extensive matrix deposition that increased dramatically over time. Im-
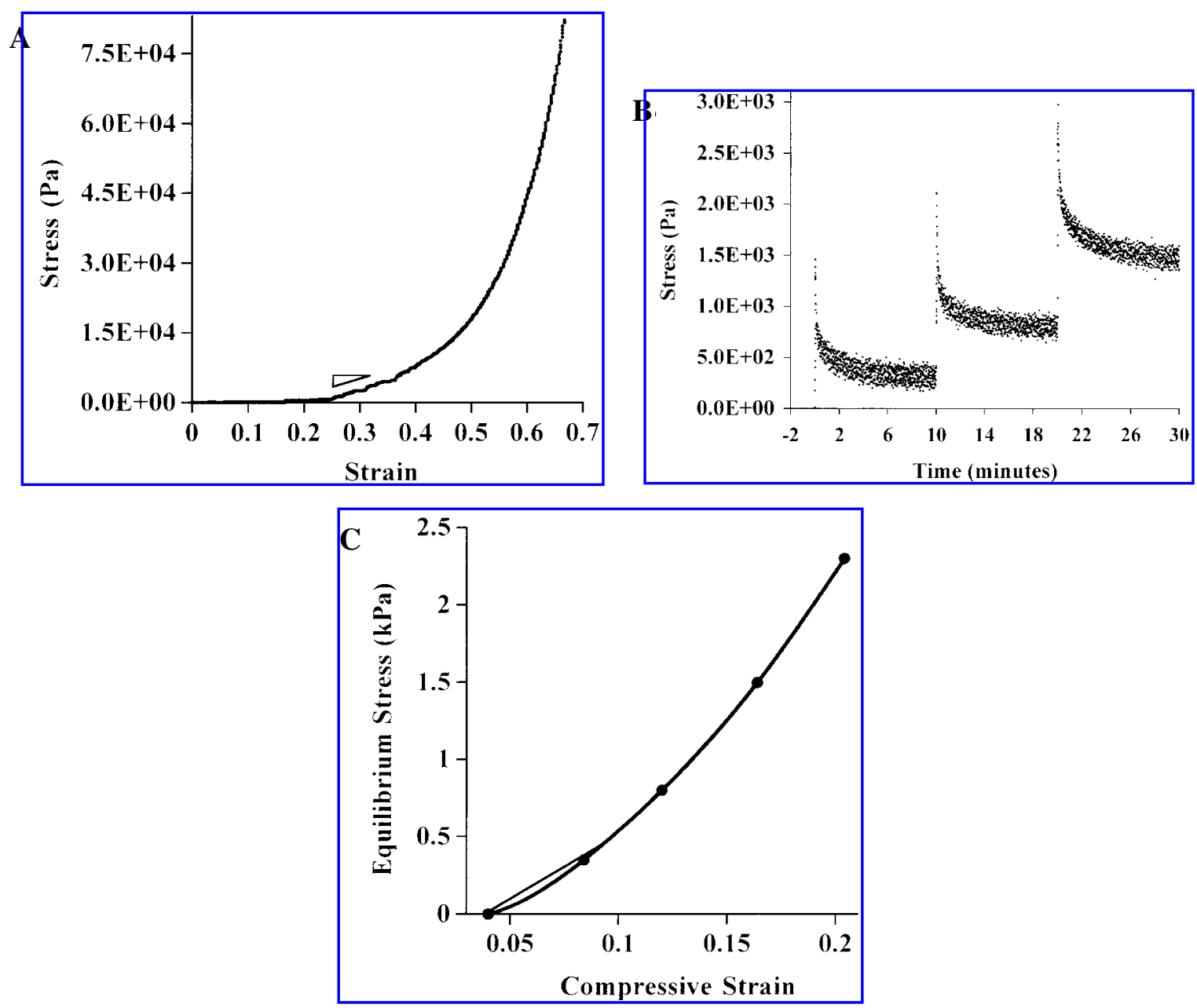

FIG. 4. A typical stress-strain curve obtained from a simple uniaxial compression test (A), stress relaxation curves obtained from a step strain viscoelastic test (B), and an interpolated equilibrium stress-strain curve constructed from a step strain viscoelastic test $(\mathbf{C})$. The slope of the triangle hypotenuse in (A) and the secant line segment in $(\mathbf{C})$ indicate the regions where the moduli were calculated. 


\section{BROWN ET AL.}

portantly, the mechanical properties of the hybrid tissues showed they were less stiff than native or engineered cartilage..$^{21,23}$

The cells seeded on the matrices proliferated over time, and deposited significant amounts of extracellular matrix. The density of cells in the hybrid tissues increased to a final value of $5.8 \times 10^{8} \mathrm{cells} / \mathrm{cm}^{3}$ after 8 weeks. This value is much larger than the range of values found for bovine articular cartilage $\left(3.0-10.0 \times 10^{7} \text { cells } / \mathrm{cm}^{3}\right)^{24}$ and very similar to that of native smooth muscle tissue. ${ }^{25}$ It is not surprising that the new tissues demonstrated significant elastin and collagen content, as SMCs typically produce large amounts of elastin on these polymer matrices, ${ }^{16,26}$ and the chondrocytes, obtained from elastic cartilage which is found in the external ear and external auditory canal, are also known to produce elastin ${ }^{27}$ and collagen $^{28}$ in vivo. The hybrid tissues also exhibited significantly increasing GAG content over time that is likely attributable primarily to the chondrocytes.

The hybrid tissue constructs were mechanically tested using two approaches, and these results demonstrate the importance of choosing an appropriate testing methodology when analyzing engineered tissues. The constant strain rate compression test led to a high modulus, likely because the modulus measured in this manner contains transient information pertaining to both the viscous and elastic properties of the tissues lumped together. These types of measurements can only be repeated or compared to other values in the literature if identical strain rates are used. In contrast, compression-stress relaxation measurements using step strains can be used to obtain equilibrium compressive moduli that are not as test condition dependent. The equilibrium compressive modulus was much smaller because the specimens were allowed to relax to a steady-state stress following each step strain. In this manner, the viscous response was dissipated and only the elastic properties of the tissues were measured. The hybrid tissues exhibited equilibrium compressive moduli that were one order of magnitude less than tissue-engineered cartilage formed from articular chondrocytes $(55 \mathrm{kPa})^{23}$ and two orders of magnitude less than native articular cartilage $(760 \mathrm{kPa}){ }^{21}$ The lower compressional mechanical properties of the hybrid tissues compared to purely cartilaginous tissues may be a result of lower GAG content and higher elastin content. Also, in contrast to the preceding referenced studies, auricular chodrocytes from elastic cartilage were used in this study, and this may lead to a less-stiff cartilaginous tissue. Future experiments in which the cells are labeled before the seeding step and the proportion of the two cell types are varied in co-culture would yield valuable information about the final cell composition of the constructs and each cell type's relative contribution to the resultant hybrid tissues' extracellular matrix components and mechanical properties.

In summary, hybrid tissues can be grown in vitro using SMCs, chondrocytes, and synthetic, biodegradable polymers. The mechanics of engineered tissues can be readily modified by combining various cell types, and this approach may ultimately be useful for reconstruction of a variety of soft tissues.

\section{ACKNOWLEDGMENTS}

The National Science Foundation (BES-9501376) and Reprogenesis funded this research, and we gratefully acknowledge Dr. Kermit Borland at Reprogenesis for providing chondrocytes.

\section{REFERENCES}

1. Anderson, J.M. Biocompatibility of tissue engineered implants. In: Patrick Jr., C.W., Mikos, A.G., and McIntire, L.V., eds. Frontiers in Tissue Engineering. New York, NY: Elsevier Science Ltd, 1998, pp. 152-165.

2. Paige, K.T., and Vacanti, C.A. Engineering new tissue: formation of neocartilage. Tissue Eng. 1, 97, 1995.

3. Langer, R., and Vacanti, J.P. Tissue engineering. Science 260, 920, 1993.

4. Mooney, D.J., and Rowley, J.A. Tissue engineering: integrating cells and materials to create functional tissue replacements. In: Park, K., ed. Controlled drug delivery challenges and strategies. American Chemical Society, 1997, pp. 333-346.

5. Kim, B-S., and Mooney, D.J. Development of biocompatible synthetic extracellular matrices for tissue engineering. Trends Biotechnol. 16, 224, 1998.

6. Puelacher, W.C., Kim, S.W., Mooney, D.J., Vacanti, J.P., Vacanti, C.A. Tissue-engineer ed growth of cartilage: the 


\section{CHONDROCYTE AND SMOOTH MUSCLE CELL HYBRID}

effect of varying the concentration of chondrocytes seeded onto synthetic polymer matrices. Int. J. Oral \& Max. Surg. 23, 49, 1994.

7. Freed, L.E., Marquis, J.C., Vunjak-Novakovic, G., Emmanual, J., and Langer, R. Kinetics of chondrocyte growth in cell-polymer implants. Biotech. Bioeng. 43, 597, 1994.

8. Freed, L.E., Grande, D.A., Lingbin, Z., Emmanual, J., Marquis, J.C., and Langer, R. Joint resurfacing using allograft chondrocytes and synthetic biodegradable polymer scaffolds. J. Biomed. Mater. Res. 28, 891, 1994.

9. Freed, L.E., Vunjak-Novak ovic, G., Biron, R.J., Eagles, D.B., Lesnoy, L.C., Barlow, S.K., and Langer, R. Biodegradable polymer scaffolds for tissue engineering. Bio/Technol. 12, 689, 1994.

10. Freed, L.E., Marquis, J.C., Nohria, A., Emmanual, J., Mikos, A.G., and Langer, R. Neocartilage formation in vitro and in vivo using cells cultured on synthetic biodegradable polymers. J. Biomed. Mater. Res. 27, $11,1993$.

11. Vacanti, C.A., Langer, R., Schloo, B., and Vacanti, J.P. Synthetic polymers seeded with chondrocytes provide a template for new cartilage formation. Plast. Reconstr. Surg. 88, 753, 1991.

12. Dunkelman, N.S., Zimber, M.P., LeBaron, R.G., Pavelec, R., Kwan, M., and Purchio, A.F. Cartilage production by rabbit articular chondrocytes on polyglycolic acid scaffolds in a closed bioreactor system. Biotechnol. Bioeng. 46, 299, 1995.

13. Mooney, D.J., Park, S., Kaufmann, P.M., Sano, K., McNamara, K., Vacanti, J.P., and Langer, R. Biodegradable sponges for hepatocyte transplantation. J. Biomed. Mater. Res. 29, 959, 1995.

14. Colton, C.K. Implantable biohybrid artificial organs. Cell Transplant. 4, 415, 1995.

15. Rothman, A., Kulik, T.J., Taubman, M.B., Berk, B.C., Smith, C.W., and Nadal-Ginard, B. Development and characterization of a cloned rat pulmonary arterial smooth muscle cell line that maintains differentiated properties through multiple subcultures. Circulation 86, 1977, 1992.

16. Kim, B-S., Putnam, A.J., Kulik, T.J., and Mooney, D.J. Optimizing seeding and culture methods to engineer smooth muscle tissue on biodegradable matrices. Biotechnol. Bioeng. 57, 46, 1998.

17. Kim, Y-J., Sah, R.L., Doong, J.Y.H., and Grodzinsky, A.J. Fluorometric assay of DNA in cartilage explants using Hoechst 33258. Anal. Biochem. 174, 168, 1988.

18. Farndale, R.W., Butle, D.J., and Barrett, A.J. Improved quantitation and discrimination of sulphated glycosaminoglycans by the use of dimethylene blue. Biochim. Biophys Acta 883, 173, 1986.

19. Hascall, V.C., and Kimura, J.H. Proteoglycans: isolation and characterization. Methods Enzymol. 82, $769,1982$.

20. Miller, E.J., and Rhodes, R.K. Preparation and characterization of the different types of collagen. Methods Enzymol. 82, 33, 1982.

21. Mow, V.C., Kuei, S.C., Lai, W.M., and Armstrong, C.G. Biphasic creep and stress relaxation of articular cartilage in compression: Theory and experiments. J. Biomech. Eng. 102, 73, 1980.

22. Quinn, T.M., and Grodzinsky, A.J. Longitudinal modulus and hydraulic Permeability of poly(methacryl ic acid) gels: effects of charge density and solvent content. Macromolecules 26, 4332, 1993.

23. Ma, P.X., Schloo, B., Mooney, D.J., and Langer, R. Development of biomechanical properties and morphogenesis of in vitro engineered cartilage. J. Biomed. Mater. Res. 29, 1587, 1995.

24. Stockwell, R.A. The cell density of human articular and costal cartilage. J. Anat. 101, 753, 1967.

25. Kleinert, L.B., Hoying, J.B., and Williams, S.K. The neointima formed in endothelial cell sodded ePTFE vascular grafts results from both cellular-hyperpla sia and extracellular-hype rtrophy. Cell Transplant. 5, 475, 1996.

26. Kim, B-S., and Mooney, D.J. Engineering smooth muscle tissue with a predefined structure. J. Biomed. Mater. Res. 41, 322, 1998.

27. de Chalain, T., Phillips, J.H., and Hinek, A. Bioengineering of elastic cartilage with aggregated porcine and human auricular chondrocytes and hydrogels containing alginate, collagen, and $\kappa$-elastin. J. Biomed. Mater. Res. 44, 280, 1999.

28. Madsen, K., von der Mark, K., van Menxel, M., and Friberg, U. Analysis of collagen types synthesized by rabbit ear cartilage chondrocytes in vivo and in vitro. Biochem. J. 221, 189, 1984.

Address reprint requests to:

Dr. David J. Mooney

Department of Chemical Engineering

University of Michigan

Ann Arbor, MI 48109-2136

E-mail: mooneyd@umich.edu 


\section{This article has been cited by:}

1. Kristina Kofler, Gerd Leitinger, Michael Kristler, Amulya K. Saxena. 2009. Smooth muscle tissue engineering for hybrid tubular organs: scanning electron microscopic investigations of cell interactions with collagen scaffolds. Journal of Tissue Engineering and Regenerative Medicine 3:4, 321-324. [CrossRef]

2. Benjamin D. Elder, Kyriacos A. Athanasiou . 2009. Effects of Temporal Hydrostatic Pressure on Tissue-Engineered Bovine Articular Cartilage ConstructsEffects of Temporal Hydrostatic Pressure on Tissue-Engineered Bovine Articular Cartilage Constructs. Tissue Engineering Part A 15:5, 1151-1158. [Abstract] [PDF] [PDF Plus]

3. Benjamin D. Elder, Kyriacos A. Athanasiou. 2008. Effects of confinement on the mechanical properties of self-assembled articular cartilage constructs in the direction orthogonal to the confinement surface. Journal of Orthopaedic Research 26:2, 238-246. [CrossRef]

4. Adam C. Aufderheide , Kyriacos A. Athanasiou . 2007. Assessment of a Bovine Co-culture, Scaffold-Free Method for Growing Meniscus-Shaped ConstructsAssessment of a Bovine Co-culture, Scaffold-Free Method for Growing Meniscus-Shaped Constructs. Tissue Engineering 13:9, 2195-2205. [Abstract] [PDF] [PDF Plus]

5. Ronny Maik Schulz, Augustinus Bader. 2007. Cartilage tissue engineering and bioreactor systems for the cultivation and stimulation of chondrocytes. European Biophysics Journal 36:4-5, 539-568. [CrossRef]

6. Shannon L. M. Dahl, Caroline Rhim, Ying C. Song, Laura E. Niklason. 2007. Mechanical Properties and Compositions of Tissue Engineered and Native Arteries. Annals of Biomedical Engineering 35:3, 348-355. [CrossRef]

7. Cindy Chung, John Mesa, Gregory J. Miller, Mark A. Randolph, Thomas J. Gill , Jason A. Burdick . 2006. Effects of Auricular Chondrocyte Expansion on Neocartilage Formation in Photocrosslinked Hyaluronic Acid NetworksEffects of Auricular Chondrocyte Expansion on Neocartilage Formation in Photocrosslinked Hyaluronic Acid Networks. Tissue Engineering 12:9, 2665-2673. [Abstract] [PDF] [PDF Plus]

8. Jerry C. Hu, Kyriacos A. Athanasiou. 2006. The Effects of Intermittent Hydrostatic Pressure on Self-Assembled Articular Cartilage Constructs. Tissue Engineering, ahead of print060510114812001. [CrossRef]

9. Jerry C. Hu , Kyriacos A. Athanasiou . 2006. The Effects of Intermittent Hydrostatic Pressure on Self-Assembled Articular Cartilage ConstructsThe Effects of Intermittent Hydrostatic Pressure on Self-Assembled Articular Cartilage Constructs. Tissue Engineering 12:5, 1337-1344. [Abstract] [PDF] [PDF Plus]

10. Nasreen Banu, Toshie Tsuchiya, Rumi Sawada. 2006. Effects of a biodegradable polymer synthesized with inorganic tin on the chondrogenesis of human articular chondrocytes. Journal of Biomedical Materials Research Part A 77A:1, 84-89. [CrossRef]

11. Jerry C. Hu , Kyriacos A. Athanasiou . 2006. A Self-Assembling Process in Articular Cartilage Tissue EngineeringA Self-Assembling Process in Articular Cartilage Tissue Engineering. Tissue Engineering 12:4, 969-979. [Abstract] [PDF] [PDF Plus]

12. Wei Seong Toh, Hua Liu, Boon Chin Heng, Abdul Jalil Rufaihah, Chao Peng Ye, Tong Cao. 2006. Combined effects of TGF $\beta 1$ and BMP2 in serum-free chondrogenic differentiation of mesenchymal stem cells induced hyaline-like cartilage formation. Growth Factors 23:4, 313-321. [CrossRef] 
13. Julie R. Fuchs, Didier Hannouche, Shinichi Terada, Sarvenaz Zand, Joseph P. Vacanti, Dario O. Fauza. 2005. Cartilage Engineering from Ovine Umbilical Cord Blood Mesenchymal Progenitor Cells. Stem Cells 23:7, 958-964. [CrossRef]

14. Hirokazu Mizuno, Amit K. Roy, Charles A. Vacanti, Koji Kojima, Minoru Ueda, Lawrence J. Bonassar. 2004. Tissue-Engineered Composites of Anulus Fibrosus and Nucleus Pulposus for Intervertebral Disc Replacement. Spine 29:12, 1290-1297. [CrossRef]

15. Jonathan B. McGlohorn, Walter D. Holder Jr. , Larry W. Grimes, Chuck B. Thomas , Karen J.L. Burg . 2004. Evaluation of Smooth Muscle Cell Response Using Two Types of Porous Polylactide Scaffolds with Differing Pore TopographyEvaluation of Smooth Muscle Cell Response Using Two Types of Porous Polylactide Scaffolds with Differing Pore Topography. Tissue Engineering 10:3-4, 505-514. [Abstract] [PDF] [PDF Plus]

16. K.J.L. Burg, T. Boland. 2003. Minimally invasive tissue engineering composites and cell printing - Injectable composites combined with tissue-printing technology for improved bioengineered devices. IEEE Engineering in Medicine and Biology Magazine 22:5, 84-91. [CrossRef]

17. Jonathan B. McGlohorn, Larry W. Grimes, Shannon S. Webster, Karen J. L. Burg. 2003. Characterization of cellular carriers for use in injectable tissue-engineering composites. Journal of Biomedical Materials Research 66A:3, 441-449. [CrossRef]

18. Alexander M. Seifalian, Alok Tiwari, George Hamilton, Henryk J. Salacinski. 2002. Improving the Clinical Patency of Prosthetic Vascular and Coronary Bypass Grafts: The Role of Seeding and Tissue Engineering. Artificial Organs 26:4, 307-320. [CrossRef]

19. Anna Loebsack, Kim Greene, Sharon Wyatt, Cathy Culberson, Catherine Austin, Rudy Beiler, Wendy Roland, Petra Eiselt, Jon Rowley, Karen Burg, David Mooney, Walter Holder, Craig Halberstadt. 2002. In vivo characterization of a porous hydrogel material for use as a tissue bulking agent. Journal of Biomedical Materials Research 57:4, 575-581. [CrossRef]

20. Steven Goldstein, Maria Moalli. 2001. Current Opinion in Orthopedics 12:5, 424-427. [CrossRef]

21. Yan Li, Shang-Tian Yang. 2001. Effects of three-dimensional scaffolds on cell organization and tissue development. Biotechnology and Bioprocess Engineering 6:5, 311-325. [CrossRef] 